\title{
Methodological Approaches to Risk Assessment of Territories of Innovative Development for Management Purposes
}

\author{
Anna A. Maltseva \\ Tver State University, Russian Federation \\ Email: 80179@list.ru
}

Doi:10.5901/mjss.2015.v6n3s5p63

\section{Abstract}

The objects of the study are the territories of innovative development, which are created in the regions to support the full cycle of production of innovative products. Risk assessment is the part of requirements to design of the development strategies of such territories and their implementation as it is shown in the paper. The author offers a comprehensive multi-level risk classification of territories of innovative development which has been investigated using expert estimation method to the average territory of this type. Designed risk maps of individual most significant components of the territories of innovative development became the basis for the allocation of risk groups that need more detailed study and development of actions to minimize them. Theoretical and methodological basis of the risk study of territories of innovative development, which is proposed in the paper, can be the basis for the development of an integrated management method of their creation and development taking into account risk factors.

Keywords: territory of innovative development, risk map, probability, risk management

\section{Introduction}

Design of territories of innovative development (TID) as special territorial structures is a long multi-step process. Providing of the effective implementation of innovative processes on the specially allocated territory should include the consistent development of main components of the TID:

- Research component

- Transfer and implementation component

- Manufacturing component

- Infrastructure component

- The component of human capital

- The marketing component

As well as at the creation phase and during the functioning of the TID as meso- economy subjects are influenced by various internal and external factors which impact on the result of the system as a whole and the individual subsystems with positive or negative effects. Innovative activity as a main activity of economic subjects of TID definitely is associated with a significant risk due to the probabilistic nature of its perspective results. Herewith investor can obtain the highest return from investing in innovative projects that follows from the classical thesis about high profit of high risk investments, and generally it shows the most potential perspective of creation TID in the region compared with similar regional structures (industrial-production zones, agriculture clusters etc.). Research and analysis of risks and risk management system designed in framework of TID should be a part of a preventive strategy for effective development of TID in a rapidly transforming internal and external environment.

TID in a view of formal (narrow) definition includes science cities, technology implementation special economic zones of federal and regional level, innovative cities. In informal terms TID can be created initiatively without a special status but current conditions of resources limitedness such territories need additional privileges, preferences which stimulate the regional authorities to participate in government projects aimed at promoting innovation in separate regions. Stimulating of innovative activity in separate areas as a whole as well as creation of TID in particular can be implement as an investment project aimed at obtaining of the effect in material form (innovative products and services) and as well as in financial form (increase of incomes in the budgets of all levels).

Assessment and risk analysis is one of the most important elements of the investment project's description as well as playing a significant role in its implementation especially in the case of TID if the project is designed for more than two 
years. In Russia and abroad there are many examples of inefficient implementation of investment projects in the sphere of innovation which case because the underestimation of the risks or illiterate management.

Thus, the identification, analysis and risks assessment focused on the subsequent creation of the risk management system in process of major innovative investment projects implementation is one of the main priorities both at the federation level and in the regions and should be an essential element of the design of territories of innovative development and their subsequent functioning.

\section{Literature Review}

Risk management have been extensively studied in the works of Russian and foreign scientists. There are researches of Hall (1998), Luhmann (1992), Lock (2007), Larson and Gray (2010), Kerzner (2009), Ericson and Doyle (2003), Furedi (1997), Flyvbjerg et al. (2003), Bernstein (1996), Boehm (1989) and others.

In his work 'Against the Gods: The Remarkable Story of Risk', Bernstein (1996) applies historical and biographical analysis of risk research. It shows that risk management methodology is the base of success stories throughout history of all civilization. The author argues that the development of the tools of probability theory and mathematical statistics formed the basis for the development of science and practice in various fields.

The research held by Furedi (2002) dedicated to the role of fear and danger in the modern world. The author shows that a culture of fear is now fostered which has a negative impact on results of operations in all spheres of human activity. The thesis about excessive prudence and risks avoidance significantly increases the probability of risk events occurrence is substantiated with specific examples. It is a real threat; their adequate assessment should be the basis for establishing of risk management effective system.

In the works of Luhmann (1992), the issues of norms and rationality of modern society and the deviations from them are considered. Study of risk research role is based on the thesis that the understanding of failures in the form of risk will allow to know the normal processes occurring in society. This suggests that the design of effective socioeconomic systems should be based on the theory of risk.

A deep investigation of risks nature and the usability degree of the system of risk management in various conditions and situations made by Ericson et al. (2003). Scientists introduced a special classification of risks including perceived directly, perceived through science and virtual risks. The study proposes to examine the admissibility and depth of activities for risk management purposes. Thus, the risk security is unacceptable in the case of e.g. virtual risks that in some cases are not real and are associated with public opinion or individual subject's views on risk actions. The study further emphasizes the need to identify the most significant, probable types of risks inherent to the system or process, and to concentrate risk management on them otherwise undue interference can cause slowed the development of the system or process.

Questions of megaprojects risks are considered in comprehensive study held by Flyvbjerg et al. (2003). The authors show that the underestimation of risk factors leads in some cases to catastrophic consequences. Planning and forecasting risks, preventive development of the risk management system in the projects of territorial development are extra needed. The study provides numerous examples of failed mega-projects and shows the role of risk events in their negative efficiency.

In modern conditions, the development of the instruments of decision making under risk and uncertainty includes design of special software which is dedicated to research in the field of risk management software engineering (e.g. Boehm, 1989; Hall, 1998). The remarkable feature of such software is the implementation of it is based on dynamic models that include many factors of risk at each stage of the project. Theoretical and empirical research including the development of risk systems analysis of their probability and significance is the basis of software tools.

In complex studies by Lock (2007), Larson and Gray (2010), Kerzner (2009) a system of risk management presents as a part of project management. The authors have comprehensively studied the elements of the risk management process including risk identification, risk assessment, risk response development and risk response control. Lock (2007) presented a methodological basis for the compilation of the risk classification matrices, which allows to structure the identified risks in terms of impact on the result and the probability. This will focus the risk management system on the most relevant and probable risks and not to extend the influence of the management system in the areas which can effectively develop independently.

Another interesting approach to risk management as a process stated in work of Castro et al. (2008). While, research by Asenova et al. (2014) is devoted to risk management on the state and regional levels. They especially mark necessary of purposed management influences on the system to minimize risks and existence of special qualify of managers for such problems decisions. Analysis has shown absence of comprehensive works to identify regional risks 
caused by innovative activity development. Thus, innovative risks are in focus of researches that are closer in subjects.

Numerous works devoted to study of reasons of insufficient efficiency of innovative activity organization in regions.

Thus, Frenkel (2003) in his investigation demonstrate results of empiric research of barriers to effectiveness implementation industrial innovation in Israel.

Several types of risks in particular of public procurement for innovation are investigated by Tarmo Kalvet and Veiko Lember (2010). But it is noted that split study of separate types of risks what is offered in publications not always can provide management system of regional level by necessary information for effectiveness management that require detailed elaboration and new tools to problems decision.

The review of literature demonstrates the particular importance of the study of risk in socio-economic systems and the need to form a clear risk management system which adequate to the real threat and significance. The formation of TID in the most general case can be considered as a mega-project and its implementation have to use a standard project management methodology and common methodical principles of project risk management. So, for the purposes of research of TID risks it is encouraged to use risk mapping as a key tool for risk analysis and assessment.

\section{Research Methodology}

The main research methods are theoretical analysis, ranging, generalization, classification that are used as at the stage of design of TID risks as well as during the development of measures to reduce them. The method of expert survey and statistical data processing are used at the stage of analysis and risks assessment. Using expert methodology caused by lack of full information about the results of potential risk events in created or operating TID.

\section{Findings and Discussion}

Differentiation of socio-economic development of regions of the Russian Federation as well as allocated in their borders special territories causes the existence of different types of risks herewith in accordance with the mission and purpose of the TID creation they can be united by common quality characteristics at the meso-level.

For research purposes, it is necessary to classify risks by levels of occurrence and influence which causes not only the definition of risk localization points but also the application of management actions focused on their minimization.

In the works Ivanov (2012) there are following levels of functioning of the economic system within which accentuated specific types of risks:

1. Mega-level: creation and demonstration of innovation risk at the global innovative world-level system level, risk factors of which are inequality of innovative development of different countries, adverse conjuncture in international financial markets etc.

2. Macro-level: creation and demonstration of innovative risk at the national innovative system level, risk factors of which are inequality of innovative development of different regions, inefficiency of management actions on the processes of innovation at the national innovative system level.

3. Meso-level: creation and demonstration of innovative risk at the regional innovation system level, risk factors of which are diversification of risks by innovative projects as well as the inefficiency of management actions on the processes of innovation at the regional innovation system level.

4. Micro-level: creation and demonstration of innovative risk at the branch, cluster innovative system level and innovative enterprise system level, risk factors of which are risks of entrepreneurship and risks of individual projects.

In the study of TID risks, it is necessary to place special emphasis to the meso-level risks as probable threats of project execution delay or its inefficiency. Management of TID at the regional level (municipality) should include management influence focused on reduction of these types of risk.

For the purposes of creation and effective functioning of TID, the synergy obtains the special importance. It is created by the participants of the innovation process of the territory due to the collaboration. If the collaboration was organized ineffective or there are stakeholders with mutually conflicting interests there is a cannibalization effect, i.e., the overall result from the interaction of TID subjects will be lower than from their individual innovative activity. Hence, the risk management system should take into account not only their individual types but also the cumulative effect that they created, i.e. their mutual reinforcement from simultaneous action. Mega- and macro-level risks are not included in the sphere of influence of organizers and coordinators of TID but their influence in some cases may be decisive and has a very negative impact on the overall result of the creation and subsequent operation of TID.

In the study, they will be considered as uncontrollable environmental factors that give rise to risks of meso- and 
micro-level, the negative impact of which can be taken into account and reduced in the management of TID. The author proposed a three-level classification of TID risks including their different types, depending on the components of the TID, level (micro- or meso-level) and the specific type belonging to one of the following groups:

- regulatory risks (political, legal, tax, environmental risks);

- financial and economic risks (inflation, foreign exchange, insurance, market risks, risks of government intervention and risks of access to capital);

- strategic risks (risks of growth opportunities, strategy selection, logistics, resource allocation, competition);

- operational risks (risks of the efficiency of management decisions, cost management and financial performance, the effectiveness of organizational systems);

- production and technical risks (risks of asset security, uninterrupted operation of equipment, infrastructure, technical compliance of equipment to solved problems, compliance of the technical specifications of products to customer expectations);

information risks (completeness risks, timeliness risks and reliability of the information risks, communications risks).

The proposed classification allows creating of TID risk management system, in which is directly determined points of application of management actions depending on the TID level and element and type of risk. The process of risk management is represented as a set of procedures consistently implemented with using the developed algorithm (Figure 1).

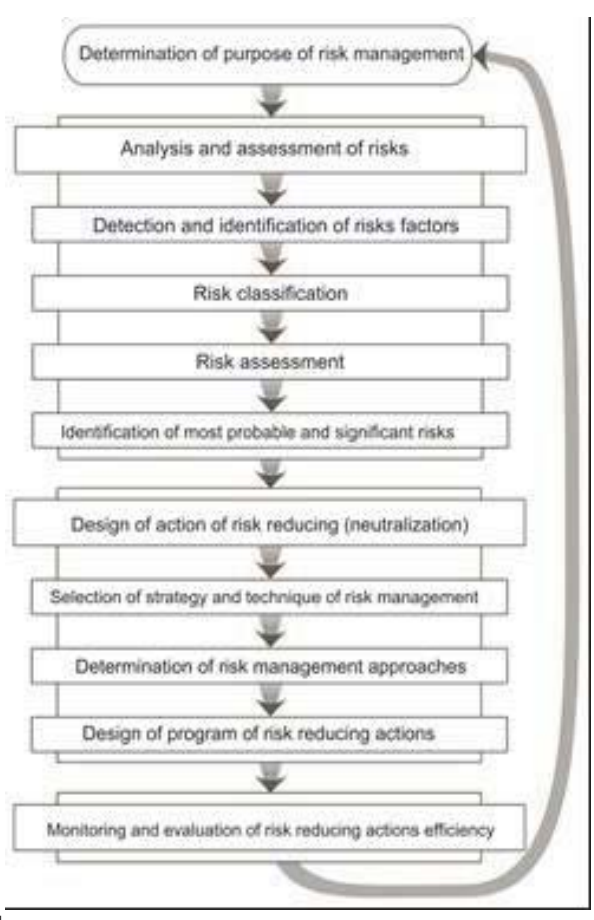

Figure 1. Risk management algorithm

Source: Maltseva, 2011, p. 154

Selection of risk assessment methodology is traditionally carried out between expert and statistical methods. Typically, statistical methods provide a more accurate evaluation while being more labor-consuming. Statistical methods are suitable for spot assessment of several kinds of risks if there is data about results of risk events in current socio-economic system. For the purposes of risk assessment and analysis of TID statistical methods in most cases are not suitable because of numerous of necessary information and absence of reliable data about the results of risk events outcomes at the moment of TID creation.

Expert assessment provides the maximum accuracy in the case of involvement of large number of experts from 
different fields having competence in decision-making at the meso-level and of consistently using of several methods of group decision making (brainstorming, Delphi technique, and others). At the stage of analysis and risk assessment composing of risks map is the most appropriate tool.

The map is the view of the risks and their significance and provides formulation of primary management goals that can be implemented in several stages:

1. Gaining expert assessments of risks types from individual polling form with a list of possible risks.

2. Analysis of the expert assessments consistency.

3. Processing of the experts survey results with assigning the category of relevance and probability to each risk.

4. Composing of risks matrix (map).

In the study the average expert assessment of these characteristics in relation to the general trends of TID was carried out, the results of which are allowed for a risk map for each of the selected components of TID. Risk map of research components is shown in this article as an example (Figure 2).

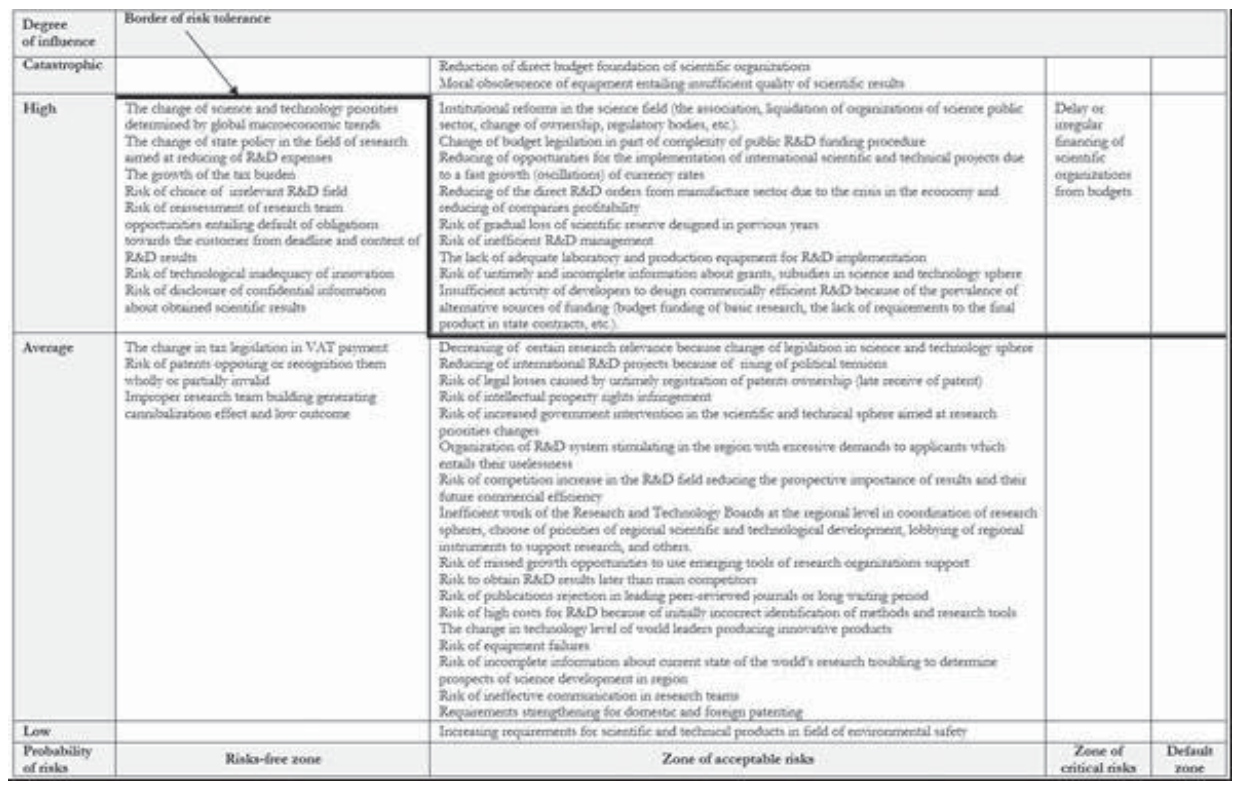

Figure 2. Risk map of TID research component

For determination of position of each type of risk in map expert assessments of its probability and significance were averaged, and it was placed in the appropriate quadrant of the matrix, each of which was is obtained using a linear scaling. Analysis showed that most of potential risks identified in research are generally below the border of risk tolerance, i.e. are acceptable. Risks that are above the border of risk tolerance are the most significant and require design of purposeful management system aimed at their neutralizing or reducing their negative impact. The greatest number of risks that requires intervention and management actions relates to the research component due to its special significance for the formation of R\&D basis of TID. The inefficiency of the research components cannot be the reason of impossibility of TID creation in selected area, a source of innovation can be import of technologies, but gradually this approach may lead to a complete loss of the research components and high dependence from other territories, as well as in a number of cases to deformation from TID to the industrial zone. Thus, the successful development of the research component can provide the basis and prerequisite for the development of other TID components.

In particular, historically formed science cities Dubna, Biysk and others became the basis of the of technologyimplementation special economic zones creation, innovation clusters and others. Just territories with developed research institutes, scientific schools are capable to save ability to generate innovation a long time while in the absence of scientific reserve, trained personnel and unique equipment the importance and life cycle of innovation proposed for implementation is much lower.

According to analysis the research component is exposed to risk most. Among the risks there are risks which 
degree of influence on the results are catastrophic or there are in zone of critical risks. Significant impact on the risks of research component has current situation in the country relating to the reform of the scientific organization system changing approaches to their financing including budget expenses. It is noted that individual expert study which is based on this classification is proposed to put the risks and methodological approaches to risk mapping component TID should be carried out in the case of a specific TID.

For management purposes the author composed the activities that can provide a relatively low loss or, on the contrary, provide an additional benefits for TID and classify them by key groups (the risks that are above the border of risk tolerance in risk map). Table 1 is an example of a measures system for the most important and possible risks of the research component.

Table 1. The measures system of risk management of TID the research component

\begin{tabular}{|c|c|}
\hline Risks & Risk Management Activities \\
\hline $\begin{array}{l}\text { Reduction of direct budget foundation of scientific } \\
\text { organizations }\end{array}$ & $\begin{array}{l}\text { Expansion of the practice and planning to participate in competitions for federal funding } \\
\text { Using of practice of regional grants of supporting prospective research directions for area } \\
\text { Strengthening of relationships between organizations and real sector of economy aimed at } \\
\text { creating a capacity and research that can get support from off-budgetary sources }\end{array}$ \\
\hline $\begin{array}{l}\text { Moral obsolescence of equipment entailing insufficient quality } \\
\text { of scientific results }\end{array}$ & $\begin{array}{l}\text { Creation of collaborative centers on the basis of scientific organizations, universities and } \\
\text { enterprises of real sector of economy } \\
\text { Development of planning system of research projects including the provision of material } \\
\text { and technical basis }\end{array}$ \\
\hline $\begin{array}{l}\text { Institutional reforms in the science field (the association, } \\
\text { liquidation of organizations of science public sector, change of } \\
\text { ownership, regulatory bodies, etc.). }\end{array}$ & $\begin{array}{l}\text { Improving the management system of research organizations at the micro-level that will } \\
\text { ensure their flexibility and adaptability to new conditions } \\
\text { Creation of spin-off companies for the development of individual research and innovation } \\
\text { projects including preferential tax treatment in accordance with legislative base }\end{array}$ \\
\hline $\begin{array}{l}\text { Change of budget legislation in part of complexity of public } \\
\text { R\&D funding procedure }\end{array}$ & $\begin{array}{l}\text { Increasing the share of off-budgetary funding in the structure of R\&D sources by } \\
\text { expanding the interaction with real sector of economy }\end{array}$ \\
\hline $\begin{array}{l}\text { Reducing of opportunities for the implementation of } \\
\text { international scientific and technical projects due to a fast } \\
\text { growth (oscillations) of currency rates }\end{array}$ & $\begin{array}{l}\text { Initiation of participation in competitions for financing research under the guidance of } \\
\text { leading international scientists } \\
\text { Organization of jobs and internships for foreign researchers in scientific organizations }\end{array}$ \\
\hline $\begin{array}{l}\text { Reducing of the direct R\&D orders from manufacture sector } \\
\text { due to the crisis in the economy and reducing of companies } \\
\text { profitability }\end{array}$ & $\begin{array}{l}\text { Organization of the system of intellectu } \\
\text { organizations including producing of } c\end{array}$ \\
\hline $\begin{array}{l}\text { Risk of gradual loss of scientific reserve designed in previous } \\
\text { years }\end{array}$ & $\begin{array}{l}\text { Development of R\&D marketing system in scientific organizations at the regional level } \\
\text { Creation of continuation of research and innovation projects } \\
\text { Improving the quality of information of research at the micro- and meso-level aimed at } \\
\text { obtaining of comprehensive and timely information about current trends in science and } \\
\text { technology }\end{array}$ \\
\hline Risk of inefficient R\&D management & $\begin{array}{l}\text { Accurate planning of R\&D } \\
\text { Preliminary collection and systematization of information about the upcoming study } \\
\text { Purposeful creation of a positive climate in the organization to facilitate effective research } \\
\text { The introduction of quality management system }\end{array}$ \\
\hline $\begin{array}{l}\text { The lack of adequate laboratory and production equipment for } \\
\text { R\&D implementation }\end{array}$ & $\begin{array}{l}\text { Using the services of collective using centers } \\
\text { Changing funding priorities of updating of material base to laboratory and production } \\
\text { equipment }\end{array}$ \\
\hline $\begin{array}{l}\text { Risk of untimely and inc } \\
\text { subsidies in science anc }\end{array}$ & $\begin{array}{l}\text { Creation and development of institutional structure, the function of which will be full and } \\
\text { timely informing about the various activities in the scientific and technical field } \\
\text { Formation of regional informative resources containing information about funding } \\
\text { opportunities in the field of science and technology and their regularly updating } \\
\text { Organization of scientific and technical events aimed at raising of enterprises and } \\
\text { organizations informing about possibilities to obtain additional financing or reimbursement } \\
\text { of expenses }\end{array}$ \\
\hline $\begin{array}{l}\text { Insufficient activity of developers to design commercially } \\
\text { efficient R\&D because of the prevalence of alternative sources } \\
\text { of funding (budget funding of basic research, the lack of } \\
\text { requirements to the final product in state contracts, etc.) }\end{array}$ & $\begin{array}{l}\text { Development of privileges and preferences system for organizations and companies that } \\
\text { manufacture the final innovative product } \\
\text { Using of co-financing mechanisms from real sector of economy allowing to set additional } \\
\text { requirements and criteria for the final scientific and technical products }\end{array}$ \\
\hline $\begin{array}{l}\text { Delay or irregular financing of scientific organizations from } \\
\text { budgets }\end{array}$ & $\begin{array}{l}\text { Diversification of funding sources of scientific organizations } \\
\text { Development of system of flexible payment schedules } \\
\text { Implementation of effective contract system with scientists including short-term } \\
\text { employment in concrete projects }\end{array}$ \\
\hline
\end{tabular}

The proposed list of activities should be concertized and improved to a specific TID. The measures system must be formed with due regard to available resources in the region and economic subjects as well as made a schedule for their implementation. While activities executing associated with their implementation costs which should exceed the potential 
effect must be pre-calculated. Risk management system should be regularly improved based on ongoing monitoring of socio-economic development and to correlate with the measures system aimed at the development of TID both within the program and the system of indicators.

\section{Concluding Remarks}

This research demonstrates the need to study and research risk factors of innovative activity at the meso-level. The resulting complex three-level risk system of TID can be the basis for selection the most significant and probable types of risks of specific TID that suggested to realize in the process of risks map composition. Risks that able to make the significant impact on the establishment and functioning of TID should be taken into account in the management system aimed at minimizing or reducing of negative impact of risks in the region.

\section{Acknowledgment}

The article was written on the public task to Tver State University by the Ministry of Education and Science of Russian Federation to research the topic "The Indicators and Risks Approach to the Territories of Innovation Development Management".

\section{References}

Asenova D., Bailey, S.J., \& McCann, C. (2014). Public sector risk managers and spending cuts: mitigating risks. Journal of Risk Research. [Online] Available: http://dx.doi.org/10.1080/13669877.2014.910683 (February 17, 2015)

Bernstein, P. (1996). Against the Gods: the remarkable story of risk. New York: John Wiley and Sons.

Boehm, B. (1989). Software Risk Management. Washington, DC: IEEE Computer Society Press.

Castro, L.M., Gulías, V.M., Abalde, C., \& Jorge, J.S. (2008). Managing the Risks of Risk Management, Journal of Decision Systems, $17(4), 501-521$.

Ericson, R.V., \& Doyle, A. (2003). Risk and Morality. Toronto: University of Toronto Press.

Flyvbjerg, B., Bruzelius, N., \& Rothengatter, W. (2003). Megaprojects and Risk: an anatomy of ambition. Cambridge: Cambridge University Press.

Frenkel, A. (2003). Barriers and Limitations in the Development of Industrial Innovation in the Region. European Planning Studies, 11(2), 115-137.

Furedi, F. (1997). The Culture of Fear: risk taking and the morality of low expectations. London and New York: Continuum International.

Hall, E. M. (1998). Managing Risk: Methods for Software Systems Development. Addison Wesley.

Ivanov, P.A. (2012). Innovative risk in management system of development of innovative systems. Ph.D. Thesis, Ufa State Aviation Technical University. Ufa.

Kalvet, T., \& Lember, V. (2010). Risk management in public procurement for innovation: the case of Nordic-Baltic Sea cities. The European Journal of Social Science Research, 23(3), 241-262.

Kerzner, H. (2009). Project Management: a system approach to planning, scheduling \& controlling. John Wiley \& Sons Inc.

Larson, E.W., \& Gray, C.F. (2010). Project Management: the managerial process. McGraw-Hill Higher Ed.

Lock, D. (2007). Project Management, MPG Books Ltd.

Luhmann, N. (1992). Risk: a sociological theory. Berlin: de Gruyter.

Maltseva, A.A. (2011). Conceptual bases of the organization and functioning of the management companies of technology parks (monograph). Kursk: South-West State University Press. 
